\title{
Short communication: Repeat breeder cows with fluid in the uterine lumen had poorer fertility
}

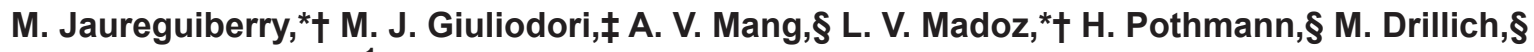 \\ and R. L. de la Sota* ${ }^{1}$ \\ ${ }^{*}$ Cátedra y Servicio de Reproducción Animal, Facultad de Ciencias Veterinarias, Universidad de La Plata (FCV-UNLP), La Plata, \\ B1900AVW, Argentina \\ †Consejo Nacional de Investigaciones Científicas y Técnicas (CONICET), Buenos Aires, C1033AAJ, Argentina \\ ¥Cátedra de Fisiología, FCV-UNLP, La Plata, B1900AVW, Argentina. \\ §University Clinic for Ruminants, Clinical Unit for Herd Health Management in Ruminants, University of Veterinary Medicine Vienna, \\ 1210 Vienna, Austria
}

\section{ABSTRACT}

The objective of the present study was to test the association between the presence of fluid in uterine lumen and the fertility of repeat breeder cows (RBC). Grazing Holstein cows that were clinically normal and were not pregnant after at least 3 consecutive inseminations were defined as RBC and included in the study ( $\mathrm{n}=$ 358). A cut-point $\geq 2 \mathrm{~mm}$ of uterine lumen visible by ultrasonography was used as indicative of the presence of fluid in the uterus. The effect of this fluid on the fertility of RBC was assessed by mixed logistic regression. Twenty percent of the RBC had $\geq 2 \mathrm{~mm}$ of fluid in their uterus, and this finding was associated with a marked reduction in the odds of conception (odds ratio $=0.46$ ). Additional intrauterine sampling revealed that 24.0\% of RBC showed signs of subclinical endometritis $[\geq 5 \%$ neutrophils in endometrial cytology (SCE)]. However, we found no agreement between the finding of uterine fluid and the diagnosis of SCE (kappa coefficient $=0.03,95 \%$ confidence interval $=-0.07$ to 0.14$)$. In conclusion, the presence of fluid $(\geq 2 \mathrm{~mm})$ in uterine lumen, detected by ultrasonography, was associated with lower fertility in RBC, but was not related to the diagnosis of SCE. Thus, ultrasonographic evaluation is an important tool to assist in assessment of RBC.

Key words: repeat breeder cow, fertility, ultrasonography, subclinical endometritis, grazing dairy cow

\section{Short Communication}

A repeat breeder cow (RBC) is described as a clinically normal cow failing to conceive in at least 3

Received May 5, 2016.

Accepted January 2, 2017.

${ }^{1}$ Corresponding author: dairydoc82@gmail.com consecutive inseminations (Casida, 1961; Yusuf et al., 2010). Nutritional disorders, infections, hormonal imbalances, genetic factors, and management decisions have all been proposed as risk factors for RBC (Båge et al., 2002; Katagiri and Takahashi, 2004; Kharche and Srivastava, 2007; Khoramian et al., 2011). General consensus is that a healthy uterine environment is a prerequisite for the normal development of the embryo (Walsh et al., 2011). However, very few studies have focused on uterine health as a possible cause of the RBC syndrome. Our assumption was that with a complete involution of the uterus, ultrasonography (US) would allow for discrimination between healthy and diseased endometrium. If so, US could be a quick and useful technique to identify fluid in the uterus, an indicator of an inflammatory process or uterine clearance deficiency. To test the hypothesis that US can be a useful diagnostic tool to identify RBC with poorer fertility, we compared the probability of pregnancy at next AI after enrollment [conception rate at first AI (CRF)] in RBC with or without fluid in their uterine cavities.

We enrolled grazing Holstein dairy cows from commercial dairy farms $(\mathrm{n}=16)$ located in Bavio $\left(34^{\circ} 54^{\prime} \mathrm{S}\right.$, $\left.58^{\circ} 23^{\prime} \mathrm{W}\right)$, Brandsen ( $\left.35^{\circ} 17^{\prime} \mathrm{S}, 58^{\circ} 23^{\prime} \mathrm{W}\right)$, and Lobos $\left(35^{\circ} 18^{\prime} \mathrm{S}, 59^{\circ} 09^{\prime} \mathrm{W}\right)$, Province of Buenos Aires, and Alejo Ledesma $\left(33^{\circ} 61^{\prime} \mathrm{S}, 62^{\circ} 61^{\prime} \mathrm{W}\right)$, Province of Córdoba, Argentina. A cow was defined as a RBC when having $\geq 3$ unsuccessful AI at normal intervals (between 17 and $24 \mathrm{~d}$ ) and not showing any clinical disease. Cows having abortions or receiving hormonal or antimicrobial treatments during the last $3 \mathrm{AI}$ were not included in the study. Selected RBC were evaluated by US via a 7.5-MHz linear array transducer (Mindray 6600Vet, Nanshan, China) to scan ovarian structures and the uterus for presence of fluid. Both uterine horns were scanned and lumen diameter from a cross sectional view at the uterine horn base on the larger uterine horn was recorded. Cows were then evaluated by manual 
Table 1. Descriptive data about the repeat breeder dairy cows $(\mathrm{n}=358)$

\begin{tabular}{lcccc}
\hline Item & Mean & SD & Median & Quartiles (25-75\%) \\
\hline Parity (no.) & 2.8 & 1.5 & 3.0 & $2.0-4.0$ \\
DIM & 275 & 160 & 226 & $173-326$ \\
Daily milk yield (kg) & 26.2 & 8.2 & 26.4 & $21.0-31.4$ \\
BCS $^{1}$ & 3.01 & 0.52 & 3.00 & $2.75-3.50$ \\
AI (no.) & 4.4 & 2.1 & 4.0 & $3.0-5.0$ \\
\hline
\end{tabular}

${ }^{1} 5$-point scale.

vaginal examination to exclude cows with purulent vaginal discharge (Williams et al., 2005; Sheldon et al., 2006). Ovarian structures, presence of fluid in uterine lumen, parity, number of services, milk production at the most recent milk recording test, and BCS $[1-5$, (Ferguson et al., 1994)] were recorded for every cow. Intrauterine samples were collected with the cytobrush technique (Kasimanickam et al., 2004), modified, and performed as described by Madoz et al. (2013). Evaluations were performed under a microscope at $400 \times$ magnification (Nikon Eclipse E200, Tokyo, Japan), where 200 cells were counted to determine the percentage of polymorphonuclear cells. The cut-point for diagnosis of subclinical endometritis (SCE) was set at $5 \%$ polymorphonuclear cells (Madoz et al., 2013).

Descriptive statistics about RBC $(\mathrm{n}=358)$ was analyzed with Proc Univariate (SAS, 2003). The odds of pregnancy (i.e., CRF) was assessed by mixed logistic regression analyses with Proc Glimmix (SAS, 2003). The models included the random effect of farm, and the fixed effect of parity ( 1 vs. $\geq 2$ ) and US finding of fluid in the uterine lumen $(<1$ vs. $\geq 1 \mathrm{~mm}$ in model 1 , and $<2$ vs. $\geq 2 \mathrm{~mm}$ in model 2 ) and their interaction. Modeling was performed by manual backward elimination with an exclusion criterion set at $P>0.1$. Agreement between diagnosis (yes, no) of uterine fluid $\geq 2 \mathrm{~mm}$ and SCE was evaluated by the kappa coefficient with Proc Freq (SAS, 2003). Statistical significance was set at $P$ $<0.05$, and a trend was set at $P<0.1$.

The prevalence of $\mathrm{RBC}$ with $\geq 1 \mathrm{~mm}$ of fluid in uterine lumen was $52 \%(186 / 358)$, whereas the prevalence of RBC with $\geq 2 \mathrm{~mm}$ of fluid in uterine lumen was $20 \%$ (73/358, Table 1$)$. Repeat breeder cows with $\geq 1 \mathrm{~mm}$ of fluid had similar odds of pregnancy as cow mates without uterine fluid (adjusted odds ratio $=0.87, P=$ 0.66 ; Table 2) given that their CRF were 20.4 versus $22.6 \%$, respectively. Conversely, $\mathrm{RBC}$ with $\geq 2 \mathrm{~mm}$ of fluid had 2-fold lower odds of pregnancy at the subsequent $\mathrm{AI}$ as cows with $<2 \mathrm{~mm}$ (adjusted odds ratio $=$ $0.46, P=0.05$; Table 2), given that they had a 12 percentage point reduction in CRF compared with their counterparts (15 vs. $27 \%$, respectively). As it has been reported that lumen size varied with the estrus cycle and parity number (Lenz et al., 2007), we assessed their effects on uterine lumen in RBC. We found that RBC having large follicles $(\geq 10 \mathrm{~mm}$ ) had more fluid in uterine lumen than cows without them, at $1.12(0.82-1.41)$ versus $0.57 \mathrm{~mm}(0.24-0.90)$, respectively [mean $(95 \%$ $\mathrm{CI}) ; P=0.004]$. Also, RBC with corpora lutea had less fluid in uterine lumen than $\mathrm{RBC}$ without $\mathrm{CL}$, at 0.66 $(0.40-0.92)$ versus $1.02 \mathrm{~mm}(0.66-1.38)$, respectively $(P$ $=0.057)$. Finally, the interaction between the presence of follicles $\geq 10 \mathrm{~mm}$ and corpora lutea had no effect on the amount of fluid in uterine lumen $(P=0.254)$. Regarding parity, primiparous and multiparous RBC had similar volumes of fluid in uterine lumen, at 0.75 $(0.35-1.15)$ versus $0.93 \mathrm{~mm}(0.70-1.16)$, respectively $(P$ $=0.390)$. According to our findings, by using a cutoff of $2 \mathrm{~mm}$, normal cows (i.e., those in estrus and multiparous) would not be considered as having an abnormal presence of fluid in their uteri. Thus, we propose that a threshold of $2 \mathrm{~mm}$ should be used to detect RBC with signs of diseased endometrium. Therefore, in agreement with our hypothesis, RBC having $\geq 2 \mathrm{~mm}$ of fluid in uterine lumen had lower odds for pregnancy than RBC without it.

To our knowledge, this is the first study evaluating the effects of fluid in uterus diagnosed by US in RBC.

Table 2. Effect of fluid in uterine lumen detected by ultrasonography (US) on conception rate at first AI after enrollment $(\mathrm{CRF})$ in repeat breeder cows $(\mathrm{n}=358)^{1}$

\begin{tabular}{lccc}
\hline US & CRF \% (no./no.) & $\mathrm{AOR}^{2}(95 \% \mathrm{CI})$ & $P$-value \\
\hline$<1 \mathrm{~mm}$ & $22.6(31 / 137)$ & Referent & 0.655 \\
$\geq 1 \mathrm{~mm}$ & $20.4(38 / 186)$ & $0.875(0.485-1.578)$ & 0.046 \\
$<2 \mathrm{~mm}$ & $26.8(68 / 254)$ & Referent & \\
$\geq 2 \mathrm{~mm}$ & $14.5(10 / 69)$ & $0.456(0.211-0.985)$ &
\end{tabular}

${ }^{1}$ Cows with missing data in the data set $(\mathrm{n}=35)$ were excluded from the statistical analysis $(358-35=323)$.

${ }^{2}$ Adjusted odds ratio. 
Our results are in line with previous reports documenting that postpartum cows (20-33 DIM) having fluid in the uterine lumen, but no signs of purulent vaginal discharge, had lower pregnancy rates than cows without fluid in the postpartum uterus (Kasimanickam et al., 2004), and that cows 21 to 27 DIM having $>2$ $\mathrm{mm}$ of fluid in uterine lumen had lower probability of pregnancy per AI (Lenz et al., 2007). Thus, our results in $\mathrm{RBC}>100 \mathrm{DIM}$ are consistent with these previous findings in postpartum cows. The diagnosis by US, however, showed a poor agreement with the diagnosis by uterine cytology. The prevalence of SCE in RBC was similar $26 \%(93 / 358)$ to the prevalence of fluid in the uterus, but no agreement occurred between the diagnosis by US and cytology (kappa $=0.03,95 \%$ CI $=-0.07$ to $0.147, P=0.55$ ). Previous studies have also reported poor agreement between tests $[\mathrm{kappa}=0.28$ and 0.25 for Kasimanickam et al. (2004) and Barlund et al. (2008) respectively], and also a weak association between uterine cytology and vaginal discharge (Dubuc et al., 2010). It must be noted that our results are for $\mathrm{RBC}$ later in lactation, whereas other studies were conducted with cows at the end of the postpartum period.

Currently 4 hypotheses, developed in the mouse model, explain the negative effects of intrauterine fluid on fertility. These hypotheses are (1) a direct toxic effect on the developing embryo; (2) mechanical interference with embryo implantation; (3) a flush out effect on the embryo; and (4) altered endometrial receptivity due to changes in gene expression ( $\mathrm{Lu}$ et al., 2013).

In conclusion, the detection by US of $\geq 2 \mathrm{~mm}$ of fluid in uterine lumen of RBC was associated with lower odds of pregnancy at the subsequent AI; therefore, this methodology may be useful in the assessment of RBC dairy cows. Evidence showed that fluid in the uterine lumen and endometrial cytology do not represent the same pathologies.

\section{ACKNOWLEDGMENTS}

We gratefully acknowledge the support of the veterinary practitioners assisting the dairy farms involved in this project, and Tomas Bautista Diaz Pernía (Lobos), Tomas Diaz Pernía (Lobos), Edgardo Alvarez (Brandsen), Horacio Lagomarsino (Alejo Ledesma), Walter Aldabe (Chascomús), and Roberto Chiavone (Bavio), who assisted in the sampling process and in the collection of the data. We also thank the farmers and the financial support of the Argentinean Ministerio de Ciencia, Tecnología e Innovación Productiva (MINCYT) and the Austrian Bundesministerium für
Wissenschaft und Forschung (BMWF) 2010-2012 and financial support of the Project: PICT2013-3260-Plan Argentina Innovadora 2020 Fondo para la Investigación Científica y Tecnológica, Argentina (FONCYT).

\section{REFERENCES}

Båge, R., H. Gustafsson, B. Larsson, M. Forsberg, and H. RodriguezMartinez. 2002. Repeat breeding in dairy heifers: Follicular dynamics and estrous cycle characteristics in relation to sexual hormone patterns. Theriogenology 57:2257-2269.

Barlund, C. S., T. D. Carruthers, C. L. Waldner, and C. W. Palmer. 2008. A comparison of diagnostic techniques for postpartum endometritis in dairy cattle. Theriogenology 69:714-723.

Casida, L. E. 1961. Present status of the repeat breeder cow problem. J. Dairy Sci. 44:2323-2329.

Dubuc, J., T. F. Duffield, K. E. Leslie, J. S. Walton, and S. J. LeBlanc. 2010. Definitions and diagnosis of postpartum endometritis in dairy cows. J. Dairy Sci. 93:5225-5233.

Ferguson, J. D., D. T. Galligan, and N. Thomsen. 1994. Principal descriptors of body condition score in Holstein cows. J. Dairy Sci. 77:2695-2703.

Kasimanickam, R., T. F. Duffield, R. A. Foster, C. J. Gartley, K. E. Leslie, J. S. Walton, and W. H. Johnson. 2004. Endometrial cytology and ultrasonography for the detection of subclinical endometritis in postpartum dairy cows. Theriogenology 62:9-23.

Katagiri, S., and Y. Takahashi. 2004. Changes in EGF concentrations during estrous cycle in bovine endometrium and their alterations in repeat breeder cows. Theriogenology 62:103-112.

Kharche, S. D., and S. K. Srivastava. 2007. Dose dependent effect of $\mathrm{GnRH}$ analogue on pregnancy rate of repeat breeder crossbred cows. Anim. Reprod. Sci. 99:196-201.

Khoramian, B., N. Farzaneh, M. Talebkhan Garoussi, and M. Mohri. 2011. Comparison of the effects of gonadotropin-releasing hormone, human chorionic gonadotropin or progesterone on pregnancy per artificial insemination in repeat-breeder dairy cows. Res. Vet. Sci. 90:312-315.

Lenz, M., M. Drillich, and W. Heuwieser. 2007. Evaluation of the diagnosis of subclinical endometritis in dairy cattle using ultrasound. Berl. Munch. Tierarztl. Wochenschr. 120:237-244.

Lu, S., H. Peng, H. Zhang, L. Zhang, Q. Cao, R. Li, Y. Zhang, L. Yan, E. Duan, and J. Qiao. 2013. Excessive intrauterine fluid cause aberrant implantation and pregnancy outcome in mice. PLoS One 8:e78446.

Madoz, L. V., M. J. Giuliodori, M. Jaureguiberry, J. Plontzke, M. Drillich, and R. L. de la Sota. 2013. The relationship between endometrial cytology during estrous cycle and cutoff points for the diagnosis of subclinical endometritis in grazing dairy cows. J. Dairy Sci. 96:4333-4339.

SAS. 2003. SAS and STAT Users Guide, Release 9.1. SAS Institute Inc., Cary, NC.

Sheldon, I. M., G. S. Lewis, S. LeBlanc, and R. O. Gilbert. 2006. Defining postpartum uterine disease in cattle. Theriogenology 65:1516-1530.

Walsh, S. W., E. J. Williams, and A. C. Evans. 2011. A review of the causes of poor fertility in high milk producing dairy cows. Anim. Reprod. Sci. 123:127-138.

Williams, E. J., D. P. Fischer, D. U. Pfeiffer, G. C. England, D. E. Noakes, H. Dobson, and I. M. Sheldon. 2005. Clinical evaluation of postpartum vaginal mucus reflects uterine bacterial infection and the immune response in cattle. Theriogenology 63:102-117.

Yusuf, M., T. Nakao, R. B. Ranasinghe, G. Gautam, S. T. Long, C. Yoshida, K. Koike, and A. Hayashi. 2010. Reproductive performance of repeat breeders in dairy herds. Theriogenology 73:1220-1229. 